\title{
COMPETITION AND COOPERATION IN A PUBLIC GOODS GAME: A FIELD EXPERIMENT ${ }^{\dagger}$
}

\author{
NED AUGENBLICK and JESSE M. CUNHA
}

\begin{abstract}
We explore the effects of competitive and cooperative motivations on contributions in a field experiment. A total of 10,000 potential political donors received solicitations referencing past contribution behavior of members of the competing party (competition treatment), the same party (cooperative treatment), or no past contribution information (control). We first theoretically analyze the effect of these treatments on the contribution behavior of agents with different social preferences in a modified intergroup public good (IPG) game. Then, we report the empirical results: Contribution rates in the competitive, cooperative, and control treatments were $1.45 \%, 1.08 \%$, and $0.78 \%$, respectively. With the exception of one large contribution, the distribution of contributions in the competitive treatment first order stochastically dominates that of the cooperative treatment. Qualitatively, it appears that the cooperative treatment induced more contributions around the common monetary reference point, while the competitive treatment led to more contributions at twice this amount. These results suggest that eliciting competitive rather than cooperative motivations can lead to higher contributions in IPG settings. (JEL D72, H41, C93)
\end{abstract}

\section{INTRODUCTION}

People's contributions to public goods are affected by the contributions of others. For example, it has been demonstrated that individuals choose to match the past contribution decisions and amounts of other contributors to the same public good, a result commonly attributed to prosocial cooperative behavior (Fischbacher, Gächter, and Fehr 2001; Frey and Meier 2004; Shang and Croson 2009). It has also been suggested that competitive motivations across groups can lead to increased public good contributions within groups (Bornstein and Ben-Yossef 1994; Bornstein, Gneezy, and Nagel 2002; Erev, Bornstein, and Galili 1993). In this article, we provide a test of this competition

${ }^{\dagger}$ We thank Muriel Niederle, Doug Bernheim, Giacomo De Giorgi, Trey Miller, Scott Nicholson, Carla Roa, and Annika Todd for comments and suggestions. This research was funded by the George P. Shultz Fund and the B.F. Haley and E.S. Shaw Fellowship, both administered through the Stanford Institute for Economic Policy Research.

Augenblick: Assistant Professor, Haas School of Business, University of California, Berkeley, Berkeley, CA 94720. Phone 510-642-1435, Fax 510-642-4769, E-mail ned@haas.berkeley.edu

Cunha: Assistant Professor, Graduate School of Business and Public Policy, Naval Postgraduate School, Monterey, CA 95060. Phone 831-656-2481, Fax 831-656-7633, E-mail jcunha@nps.edu hypothesis using a natural field experiment, and we directly compare the effects of competitive and cooperative donating environments. Specifically, we solicited donors engaged in a competitive public good game and presented them with information about the contributions of members of their own group, contributions of members of the competing group, or no information about the contribution of others (the control group). Our results suggest that competitive motives are potentially more useful in driving higher contribution rates and total contributions.

The field experiment involved sending one of three types of solicitation postcards to 10,000 potential donors to a Democratic candidate's 2008 campaign for the U.S. House of Representatives. Two of the postcard designs contained a reference to average past contribution amounts of a reference group: either Democrats (the cooperative treatment) or Republicans (the competitive treatment). Specifically, the reference in the postcard for the competitive treatment reads "Small Republican contributions have been averaging

\section{ABBREVIATION}

IPG: Intergroup Public Good 
\$28" while the reference in the postcard for the cooperative treatment reads "Small Democratic contributions have been averaging \$28." 1 As both treatments reference the same monetary amount, we can independently identify the differential effect of the referenced group. The third postcard type (the control treatment) neither referenced past contribution amounts, nor mentioned a reference group. As such, we can also identify the joint effect of referencing a group (one's own group or the competing group) and a past reference amount.

The political contribution environment we study can be seen as a close analog of the intergroup public good (IPG) game suggested by Rapoport and Bornstein (1987), which is commonly used in laboratory research on competitive effects in public good games. In the IPG, individuals in two groups choose contribution amounts and members of the group with the largest collective amount of contributions are given a larger reward than members of the other party. We extend this model to more closely match the political contribution environment, in which contributions lead to a higher chance of a party winning the race, giving a larger benefit to donors to that party. We then theoretically analyze the effect of our three treatments in this environment on an agent with Charness-Rabin (2002) social preferences. The model predicts that the cooperative treatment will lead to either higher contributions or contributions closer to the reference point, depending on the agent's social preferences. The model also predicts that the competitive treatment will lead to higher contributions if agents feel a strong sense of negative reciprocity toward members of the other party (which seems plausible in the 2008 political environment). ${ }^{2}$

In the field experiment, we find that the contribution rates in the competitive, cooperative, and control treatments were $1.45 \%, 1.08 \%$, and $0.78 \%$, respectively. Furthermore, with the exception of one larger contribution, the distribution of contributions in the competitive treatment first order stochastically dominates that of the

1. Note that these are true statements given that we define "small" contributions as those less than $\$ 75$ (see Section II). For a similar use of this type of definition, see Frey and Meier (2004).

2. We note that this model is simplified in the sense that it does not fully take into account important institutional factors (such as political favors that might come with higher contributions) and ignores certain strategic issues (e.g., we only model one agent's decision rather than a full equilibrium). cooperative treatment. The cooperative treatment induced more contributions concentrated near the common reference point $(\$ 28)$, while the competitive treatment induced more contributions at nearly twice the level of this reference point (about \$50). As a result of these effects at both the intensive and extensive margins, the cooperative and competitive treatments yielded $15 \%$ and $82 \%$ higher total monetary contributions than the control, respectively. We temper these results by noting that the contribution rate and the total amount collected from the cooperative treatment is not statistically significantly different than that of the control, a result driven by low contribution rates.

Our results suggest that intragroup competition can drive higher contribution rates and amounts than intergroup cooperation in a natural public good environment. This is an important finding for two reasons. First, it suggests that the competitive desire for own-group victory could be a strong motivator in other public good games. Second, this is the first article to our knowledge that tests the impacts of different contribution motivations in a political environment. Political campaigns are one of the most important contribution environments, not least because of the sums of money involved, and our findings provide important insights into incentives for such contributions.

Several papers have previously estimated the effect of social information on solicitation behavior. ${ }^{3}$ Frey and Meier (2004) conducted a field experiment in which students were asked to contribute to a university fundraising campaign. The authors find an increase, albeit small, in the contribution rate when students were informed that a higher percentage of students had contributed to the campaign in the past. Similarly, Shang and Croson (2006), Shang, Reed, and Croson (2008), and Shang and Croson (2009) use multiple field experiments with a public radio fundraising drive to study the effect of social information on contribution amounts. These papers use a variety of social comparisons ("A member like you just contributed ...", "She just contributed ...") and an array of reference points to show that

3. A large literature has also studied the independent effect of reference points on contribution behavior in cooperative situations (DeJong and Oopik 1992; Desmet and Feinberg 2003; Fraser, Hite, and Sauer 1988; Schibrowsky and Peltier 1995; Smith and Berger 1996; Weyant 1996). Broadly speaking, this literature concludes that the relative size of the referenced amount matters, with higher reference points increasing contribution amounts yet decreasing the propensity to contribute. 
social comparisons can affect contribution rates and amounts.

Several papers have also studied the effect of intergroup competition on intragroup cooperation. In the laboratory, Bornstein and Ben-Yossef (1994) show that participants are twice as likely to cooperate in a prisoner's dilemma game when it is embedded in a game with intragroup competition. Similarly, Bornstein, Gneezy, and Nagel (2002) demonstrate that intergroup competition increases intergroup efficiency in a minimaleffort coordination game. In a laboratory-like field experiment, Erev, Bornstein, and Galili (1993) show that subjects' productivity increases (in picking oranges) when there is competition across groups. Most of this research explores competitive effects using the IPG or close variations. $^{4}$

In that we discuss our empirical results through the theoretical lens of competitive (spite) motivations, this article is related to a literature which studies the effect of these motivations in auctions, both theoretically (Morgan, Steiglitz, and Reis 2003) and experimentally (Eliaz, Offerman, and Schotter 2008; Filiz-Ozbay and Ozbay 2007; Ockenfels and Selten 2005). Furthermore, as we study a public-goods game with elements of competition and exogenous rewards, the article relates to studies of other fundraising mechanisms with these characteristics, such as tontines (Lange, List, and Price 2007) and multiple-prize lotteries (Corazzini, Faravelli, and Stanca 2009; Onderstal, Schram, and Soetevent 2013).

More generally, this article relates to a growing literature on the motivations for charitable contributions and the effect of various incentives to make charitable contributions, such as matching schemes (Huck and Rasul 2011), seed money (List and Lucking-Reiley 2002), rebates (Eckel and Grossman 2008), and gift exchange (Falk 2007).

In Section II, we describe the contribution environment and the field experiment. Section III presents a simple model of the effect of social preferences on contributions in a stochastic IPG game that matches our field environment. Section IV presents the experimental results on differential contribution rates and amounts across treatment groups. Section V concludes with a discussion of these results.

4. The exception is Bornstein, Gneezy, and Nagel (2002), who use a "minimal-effort" game where the winning group is determined by comparing the smallest contribution made in each group.

\section{THE FIELD EXPERIMENT}

\section{A. The Congressional Election and the Intervention}

The experiment took place during a 2008 campaign for the U.S. House of Representatives in the state of Florida. We worked with the Democratic challenger who had not previously run for a national public office; the incumbent was a long-serving Republican. Informal discussions with local Democrats made it clear that two factors were contributing to a general belief that their candidate could win the race, and this belief was driving contributions. First, there was expected to be a higher-than-usual turnout amongst Black voters for the concurrent presidential campaign (Barack Obama vs. John McCain) - most Black voters in the district are Democrats and it was believed they would also vote the for the Democratic Congressional candidate. Second, the majority of votes cast in-district for the U.S. Senate race 2 years earlier had been for the Democratic candidate, signaling a shift in political preferences.

Working with the candidate, we identified 10,000 potential donors who were to receive a solicitation postcard in the final weeks of the campaign. This sample was chosen from a list of past donors to Democratic campaigns and a set of voters identified as strong Democrats from their participation in past primary elections (as determined by public voting records). The majority (about 78\%) of the recipients lived in the congressional district contested by our candidate, while the remainder lived in other districts in Florida. The campaign targeted Democrats outside the district because of a belief that individuals care about not just their own representative, but also about the overall representation of Democrats in Congress.

Subjects received one of three treatment postcards. Each contained a large picture of the candidate and a short message urging them to contribute to the campaign: see Figure 1. The text of the postcard was written to convey the message that the race was close and that marginal contributions could be pivotal. The main difference between the treatments was a single emphasized sentence in the center of the message $^{5}$ :

5. The other difference is that the $\$ 28$ reference point in the cooperative and competitive treatments is repeated in small text stating how contributions can be spent (see Figure 1). 
FIGURE 1

The Solicitation Postcards
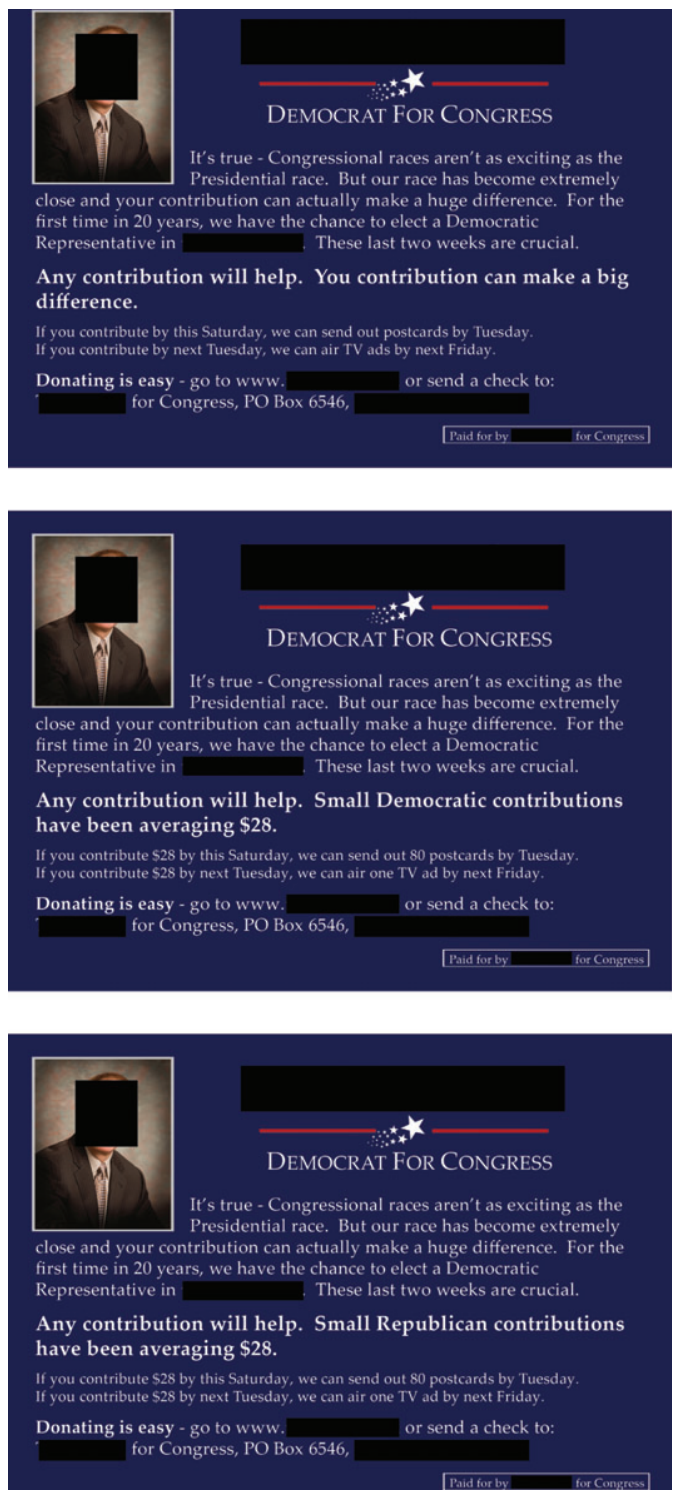

Note: From top to bottom, the control, cooperative, and competitive treatments.

Control treatment: "Your contribution can make a big difference."

Cooperative treatment: "Small Democratic contributions have been averaging \$28."

Competitive treatment: "Small Republican contributions have been averaging \$28."
Past contribution data were obtained from the publicly available Federal Election Commission online database (www.fec.gov). We implicitly define "small" contributions as those less than \$75: the average of current election cycle contributions less than $\$ 75$ was equal for our Democratic candidate (\$28) and the Republican candidate (\$28) at this cutoff. ${ }^{6}$

\section{B. Data and Identification}

Recipients were randomly assigned to one of the three treatment groups using a simple randomization algorithm. After the election, we obtained demographic and voting characteristics of the recipients by matching names and addresses with Florida's public-record voter files. This match was successful for $88 \%$ of the sample, including all of the actual contributors. ${ }^{7}$ In order to include nonmatched recipients in the regression analysis below, we include an indicator for missing demographic information.

Table 1 summarizes our data. Column 1 characterizes the sample as a whole. Recipients are mostly older (around 61 years old) and White (around 84\%), largely reflecting the demographic make-up of the Democratic voting population in this congressional district. As expected, the majority of the sample consists of registered Democrats, although 6\% are registered Republicans. Furthermore, $72 \%$ of the postcard recipients had voted in a past primary, reflecting a relatively large interest in politics amongst this sample.

Columns 2 through 4 of Table 1 contain mean characteristics by treatment group, and columns 5 through 7 contain $p$ values from $F$-tests of the pair-wise equality of the means across groups. These data suggest the randomization was successful; the pretreatment demographics are for the most part indistinguishable across groups. For two variables, there are significant differences across groups: age differs between control and both cooperative and competitive groups, and

6. This specific (implicit) cutoff choice was chosen so that we could truthfully state the same reference amount for both experimental groups. However, by not explicitly stating the cutoff amount, there is a concern that people might interpret these messages differently depending on their definition of "small." Campaign staff believed the message would be interpreted in a consistent way and (strongly) discouraged the message " ... contributions less than $\$ 75$ have been averaging \$28" due to its specificity and complexity.

7. Unmatched recipients likely either had significantly misspelled names or had recently moved. Unmatched recipients account for $12.25 \%, 13.13 \%$, and $12.42 \%$ of the control, competitive, and cooperative groups, respectively (differences between these levels are not statistically significant). 
TABLE 1

Pretreatment Summary Statistics and Balance Across Groups

\begin{tabular}{|c|c|c|c|c|c|c|c|}
\hline & $\begin{array}{l}\text { All } \\
\text { (1) }\end{array}$ & $\begin{array}{l}\text { Control } \\
\text { (2) }\end{array}$ & $\begin{array}{c}\text { Cooperative } \\
\text { (3) }\end{array}$ & $\begin{array}{c}\text { Competitive } \\
\text { (4) }\end{array}$ & $\begin{array}{c}(2)=(3) \\
p \text { value } \\
\quad(5)\end{array}$ & $\begin{array}{c}(2)=(4) \\
p \text { value } \\
\quad(6)\end{array}$ & $\begin{array}{c}(3)=(4 \\
p \text { value } \\
\quad(7)\end{array}$ \\
\hline Male & 0.47 & $\begin{array}{c}0.46 \\
(0.01)\end{array}$ & $\begin{array}{c}0.48 \\
(0.01)\end{array}$ & $\begin{array}{c}0.47 \\
(0.01)\end{array}$ & .23 & .57 & .53 \\
\hline Age & 61.42 & $\begin{array}{l}61.90 \\
(0.26)\end{array}$ & $\begin{array}{l}61.14 \\
(0.26)\end{array}$ & $\begin{array}{l}61.22 \\
(0.26)\end{array}$ & $.04 * *$ & $.07 *$ & .82 \\
\hline Registered Democrat & 0.91 & $\begin{array}{c}0.90 \\
(0.01)\end{array}$ & $\begin{array}{c}0.91 \\
(0.01)\end{array}$ & $\begin{array}{c}0.90 \\
(0.01)\end{array}$ & .22 & .00 & .22 \\
\hline Registered Republican & 0.06 & $\begin{array}{c}0.07 \\
(0.00)\end{array}$ & $\begin{array}{c}0.05 \\
(0.00)\end{array}$ & $\begin{array}{c}0.06 \\
(0.00)\end{array}$ & $.07 *$ & .63 & .18 \\
\hline Registered with other party & 0.01 & $\begin{array}{c}0.01 \\
(0.00)\end{array}$ & $\begin{array}{c}0.01 \\
(0.00)\end{array}$ & $\begin{array}{c}0.01 \\
(0.00)\end{array}$ & .68 & .12 & .25 \\
\hline Registered with no party & 0.03 & $\begin{array}{c}0.03 \\
(0.00)\end{array}$ & $\begin{array}{c}0.03 \\
(0.00)\end{array}$ & $\begin{array}{c}0.02 \\
(0.00)\end{array}$ & .81 & .83 & .65 \\
\hline Voted in a primary & 0.72 & $\begin{array}{c}0.72 \\
(0.01)\end{array}$ & $\begin{array}{c}0.72 \\
(0.01)\end{array}$ & $\begin{array}{c}0.72 \\
(0.01)\end{array}$ & .68 & .51 & .80 \\
\hline Lives outside the district & 0.22 & $\begin{array}{c}0.22 \\
(0.01)\end{array}$ & $\begin{array}{c}0.22 \\
(0.01)\end{array}$ & $\begin{array}{c}0.23 \\
(0.01)\end{array}$ & .78 & .65 & .47 \\
\hline White & 0.84 & $\begin{array}{c}0.84 \\
(0.01)\end{array}$ & $\begin{array}{c}0.83 \\
(0.01)\end{array}$ & $\begin{array}{c}0.85 \\
(0.01)\end{array}$ & .26 & .88 & .20 \\
\hline Black & 0.11 & $\begin{array}{c}0.11 \\
(0.01)\end{array}$ & $\begin{array}{c}0.11 \\
(0.01)\end{array}$ & $\begin{array}{c}0.10 \\
(0.01)\end{array}$ & .54 & .18 & .46 \\
\hline Observations & 8,712 & 2909 & 2913 & 2890 & & & \\
\hline Missing public-record voter demographics & 0.12 & $\begin{array}{c}0.12 \\
(0.01)\end{array}$ & $\begin{array}{c}0.12 \\
(0.01)\end{array}$ & $\begin{array}{c}0.13 \\
(0.01)\end{array}$ & .96 & .37 & .34 \\
\hline Observations & 9,954 & 3,315 & 3,318 & 3,321 & & & \\
\hline
\end{tabular}

Notes: All characteristics were obtained from Florida's public-record voter files and were self-reported when the recipient registered to vote. A voter is defined as having voted in a primary if they voted in any primary election between the years of 1996 and 2008. Standard errors are in parentheses.

$* * * p<.01 ; * p<.05 ; * p<.1$.

there are significantly more registered Republicans in the control versus cooperative groups. Under the assumption that the sample is also balanced across unobserved covariates of contribution outcomes, the random assignment to treatment allows us to identify the causal impact of treatments relative to one another.

Soon after the mailings were sent out, the candidate began to receive contributions in the mail and online which were recorded by campaign staff. Two data collection issues are of note.

First, concurrent with our experiment, the candidate was involved in other campaign activities (such as a fund-raising concert) which may have prompted contributions from recipients of the experimental postcards. In most cases, such contributions were identified by the campaign staff and we do not include them in our analysis. In a few cases, however, it was impossible to determine the impetus for a contribution. To isolate the impact of our solicitation postcards, we only use contributions that were made 1 week after the receipt of the mailing. The results presented below are robust to changes in this window of acceptance.
Second, despite attempts by campaign staff to purge the list of duplicates before the mailings were sent out, it was discovered that 46 recipients were accidentally sent two postcards (about $0.5 \%$ of the sample), and hence were placed in two different treatment groups. This oversight occurred because the full sample was created using several lists of past donors, and some donors were on more than one list. These recipients were thus exposed to more than one treatment, making it is impossible to identify the effect of either treatment independently for this group. Therefore, we drop them in the subsequent analysis, leaving a total of 9,954 subjects. After this correction, the control, competitive, and cooperative treatments contain $3,315,3,321$, and 3,318 subjects, respectively. There is no significant difference in the percentage of duplicated subjects in each treatment group.

\section{A MODEL OF SOCIAL PREFERENCES IN A STOCHASTIC IPG GAME}

In this section, we model the effect of social preferences on contributions in a simple game 
that mirrors our field environment. In the experiment, recipients are asked to contribute money to their preferred candidate, knowing that current and past contributions to both candidates will affect the likelihood that each candidate will win. In the model, a player must make a contribution to his/her own team given the previous contributions to his/her own team and another team, knowing that a higher contribution will increase the likelihood of his/her team winning a prize. We explore the effect of the three different treatments in our experiment on a player with social preferences.

In the game, there are three agents (player 1, player 2, and player 3) and two teams. Players 1 and 3 belong to the "odd" team and player 2 belongs to the "even" team. In the game, each agent makes a monetary contribution to his/her team. First, player 1 contributes $c_{1} \in \mathfrak{R}^{+}$and player 2 contributes $c_{2} \in \mathfrak{R}^{+}$. Player 1 and player 2 's decisions are taken as exogenous to the model and are not analyzed. We will focus on the monetary contribution decision $c_{3} \in \mathfrak{R}^{+}$of player 3 , which occurs after player 1 and player 2 's decisions.

After all agents make their contribution decisions, the winning team is probabilistically chosen based on the difference in the total level of contributions given to each team. Specifically, the "odd" team is chosen as the winning team with probability $P(\Delta c)$ where $\Delta c \equiv c_{1}-c_{2}+c_{3}$. We assume that $P(\cdot)$ is continuous and that $P(\Delta c) \in[0,1], P^{\prime}(\Delta c)>0$, and that, for some $x$, $P^{\prime \prime}(\Delta c)>0$ for all $\Delta c<x$ and $P^{\prime \prime}(\Delta c)<0$ for all $\Delta c>x$. Standard increasing functions that map $\mathfrak{R} \rightarrow[0,1]$, such as the logistic function and the cumulative normal distribution function, fit these criteria. Members of the winning team receive a payoff $w$, while members of the losing team receive no payoff. Therefore, the expected material payoff for each player is:

$$
\begin{aligned}
& \pi_{1}=w \cdot P(\Delta c)-c_{1} \\
& \pi_{2}=w \cdot(1-P(\Delta c))-c_{2} \\
& \pi_{3}=w \cdot P(\Delta c)-c_{3} .
\end{aligned}
$$

In modeling the players' preferences, we import the model of social preferences from Charness and Rabin (2002). This model incorporates additional utility terms that capture positive social preferences (such as inequity aversion or social welfare preferences) and negative social preferences (such as the desire to punish an agent who has "misbehaved"). If agent $A$ receives material payoff $\pi_{A}$ and agent $B$ receives material payoff $\pi_{B}$, agent $B$ 's utility is represented as:

$$
\begin{aligned}
U_{B}= & (1-\rho \cdot r-\sigma \cdot s-\theta \cdot q) \pi_{B} \\
& +(\rho \cdot r+\sigma \cdot s+\theta \cdot q) \pi_{A}
\end{aligned}
$$

where

$r=1$ if $\pi_{B}>\pi_{A}$ and $r=0$ otherwise

$s=1$ if $\pi_{B} \leq \pi_{A}$ and $s=0$ otherwise

$q=-1$ if agent A has "misbehaved" and $q=0$ otherwise.

In the model, agent $B$ places (potentially negative) weight on agent $A$ 's payoff. When the other agent has not "misbehaved," agent $B$ places weight $\rho$ on agent $A$ 's payoff when agent $B$ is ahead, but places weight $\sigma$ on the agent $A$ 's payoff when agent $B$ is behind. It is assumed that $\rho \in[0,1]$ so that agents never put negative weight on their own payoff. It is assumed that $\sigma<\rho$ to capture the idea that agents care less about the other person when the other person is ahead. Abstracting from the parameter $\theta, \sigma<0$ models "inequity aversion" in the sense that an agent prefers a higher personal material payoff but also prefers that both agents' payoffs are equal. Conversely, $\sigma>0$ models "social welfare preferences" in the sense that an agent always prefers more for herself and the other agent. We will discuss both of these situations below.

The parameter $\theta$ captures a form of reciprocity. When the other agent "misbehaves," $\theta$ is subtracted from the weight placed on the other player. If the desire for reciprocity is relatively strong $(\theta>\rho)$, the agent is always willing to give up personal material payoff in order to reduce the material payoff of a misbehaving other agent. In our game, we will assume that player 3 always perceives player 1 (a member of the same team) as not "misbehaving" and player 2 (a member of the other team) as "misbehaving." In this sense, reciprocity is capturing the competitive motivations inherent in our setting.

We model the experiment as affecting the way that player 3 views and solves his/her maximization problem. That is, when the problem is framed with reference to another player, player 3 "focuses" more on his/her social preferences with respect to this other player. For expositional purposes, we model extreme effects of the treatments, such that player 3 either has no social preferences (control treatment), social preferences only concerning his/her teammate (cooperative treatment), or social preferences only concerning his/her opponent (competitive treatment). In reality, we believe that our treatments 
do not lead to these extremes, but rather move subjects toward these extremes (leading to the same comparative statics as our model).

Thus, in the "control" condition, when player 3 does not see any cue that refers to another player, he/she does not take any social preference terms into account and simply maximizes his/her material payoff:

$$
U_{3}^{\text {cont }}=\pi_{3} .
$$

In the "cooperative" treatment, when player 3 sees a cue that refers to a member of his/her own team (player 1 ), he/she solves the problem considering his/her social preferences with respect to player 1:

$$
\begin{aligned}
U_{3}^{\text {coop }}= & (1-\rho) \cdot \pi_{3}+(\rho) \pi_{1} \quad \text { if } \pi_{3}>\pi_{1} \\
& (1-\sigma) \cdot \pi_{3}+(\sigma) \pi_{1} \quad \text { if } \pi_{3} \leq \pi_{1} .
\end{aligned}
$$

Finally, in the "competitive" treatment, when player 3 sees a cue that refers to a member of the other team (player 2), he/she solves the problem considering his/her social preferences with respect to player 2 :

$$
\begin{aligned}
U_{3}^{\text {comp }}= & (1-\rho+\theta) \cdot \pi_{3}+(\rho-\theta) \pi_{2} \\
& \text { if } \pi_{3}>\pi_{2} \\
& (1-\sigma+\theta) \cdot \pi_{3}+(\sigma-\theta) \pi_{2} \\
& \text { if } \pi_{3} \leq \pi_{2} .
\end{aligned}
$$

We define $c_{3}^{\text {cont }}, c_{3}^{\text {coop }}$, and $c_{3}^{\text {comp }}$ as contributions that maximize the respective utility functions. ${ }^{8}$ This setup produces the following results about the level of player 3's contributions in the different treatments:

PROPOSITION 1. (1) If $\sigma>0$ (social welfare preferences) then $c_{3}^{\text {coop }} \geq c_{3}^{\text {cont }}$

(2) If $\sigma<0$ and $\left\{c_{3}^{\text {cont }}, c_{3}^{\text {coop }}\right\}>0$ (inequity aversion) then $\left|c_{3}^{\text {coop }}-c_{1}\right| \leq\left|c_{3}^{\text {cont }}-c_{1}\right|$

(3) If $\theta>\rho$ (relatively high reciprocity) then $c_{3}^{\text {comp }} \geq c_{3}^{\text {cont }}$

Note: Relations (1) and (3) hold strictly true if contributions are positive in all treatments.

Proof. See Appendix.

The first two statements compare the contributions of player 3 in the cooperative treatment versus the control treatment. If player 3

8. These solutions are generically unique. In the case of multiple solutions, we always choose the highest contribution for consistency across conditions. has social welfare preferences, he/she will always contribute more in the cooperative treatment. Intuitively, this occurs because player partially internalizes the positive effect of his/her contribution on his/her teammate, player 1 . If player 3 has inequity aversion preferences, he/she will contribute closer to his/her teammate's contribution in the cooperative treatment, because he/she dislikes contributing relatively more than his/her teammate. The third statement compares the contributions of player 3 in the competitive versus the control treatment. As long as player 3 has a strong enough preference for negative reciprocity such that he/she is willing to lower his/her own payoff to lower the payoff of player 2-a member of the opposing team-he/she will contribute more in the competitive treatment than the control treatment.

Depending on whether people have social welfare preferences or preferences for inequity aversion, the model predicts that the cooperative treatment will lead to either higher contributions or contributions closer to the reference point compared to the control treatment. The effect of the competitive treatment depends on the level of negative reciprocity felt toward members of the opposing team. Previous research (Chen and Li 2009) documented significant negative reciprocity toward players of a randomly assigned outgroup when the stakes are relatively small. Presumably, this effect is larger for groups with opposing political affiliations in a heated political race. If Democrats do in fact feel very strong negative reciprocity when making distributional decisions involving Republicans, the model predicts larger contributions in the competitive treatment compared to the control treatment.

We make two final notes. First, while Proposition 1 does not fully address the extensive margin of contribution behavior, this is possible with a slightly more complicated model. For example, if $\sigma>0$, there are some parameters for which $c_{3}^{\text {cont }}$ will be zero, but $c_{3}^{\text {coop }}$ will be positive. If player 3 was given a stochastic additional cost, it would be possible to show that player 3 would be more likely to contribute in the cooperative treatment than the control treatment if $\sigma>0$.

Second, the model assumes that player 3 knows the other players' contribution levels prior to the treatment. If, in fact, the reference point in our experiment did not match subjects' expectations, contributions could be affected in ways not captured in the model. For example, if player 3 learned that player 2 donated an unexpectedly very high amount, he/she would 
TABLE 2

Contribution Rates and Amounts Across Treatment Groups

\begin{tabular}{|c|c|c|c|c|c|c|c|c|}
\hline & $\begin{array}{l}\text { All } \\
(1)\end{array}$ & $\begin{array}{c}\text { Control } \\
\text { (2) }\end{array}$ & $\begin{array}{c}\text { Cooperative } \\
\text { (3) }\end{array}$ & $\begin{array}{c}\text { Comparative } \\
\text { (4) }\end{array}$ & $\begin{array}{l}(2)=(3) \\
p \text { Value } \\
(5)\end{array}$ & $\begin{array}{l}(2)=(4) \\
p \text { Value } \\
(6)\end{array}$ & $\begin{array}{c}(3)=(4) \\
p \text { Value } \\
(7)\end{array}$ & $\begin{array}{c}(2)=(3)=(4) \\
p \text { Value } \\
(8)\end{array}$ \\
\hline Contribution rate & 1.11 & $\begin{array}{c}0.78 \\
(0.18)\end{array}$ & $\begin{array}{l}1.08 \\
(0.18)\end{array}$ & $\begin{array}{l}1.45 \\
(0.18)\end{array}$ & .24 & $.01 * * *$ & .16 & $.04 * *$ \\
\hline Mean contribution $(\$)$ & 0.70 & $\begin{array}{c}0.53 \\
(0.16)\end{array}$ & $\begin{array}{c}0.60 \\
(0.16)\end{array}$ & $\begin{array}{c}0.96 \\
(0.16)\end{array}$ & .74 & $.06 *$ & .12 & .13 \\
\hline $\begin{array}{l}\text { Mean contribution } \\
\text { conditional on } \\
\text { contributing }(\$)\end{array}$ & 63.10 & $\begin{array}{c}67.31 \\
(12.17)\end{array}$ & $\begin{array}{c}55.64 \\
(10.34)\end{array}$ & $\begin{array}{l}66.42 \\
(8.95)\end{array}$ & .47 & .95 & .43 & .68 \\
\hline Number of contributors & 110 & 26 & 36 & 48 & & & & \\
\hline Number of recipients & 9,954 & 3,315 & 3,318 & 3,321 & & & & \\
\hline
\end{tabular}

Note: Standard errors in parentheses.

$* * * p<.01 ; * * p<.05 ; * p<.1$.

potentially lower his/her contribution because he/she would have to contribute a very large amount to counter these contributions. Similarly, if player 3 learned that player 1 donated an unexpectedly very high amount, he/she would potentially lower his/her contributions because his/her contributions would have little additional effect. We abstract from this additional informational effect because it is often ambiguous and depends largely on the precise shape of $P(\cdot)$ and the initial expectations of player 3 , which are clearly difficult to model.

\section{RESULTS}

\section{A. Contribution Rates}

Our first main result concerns contribution rates. Table 2 contains contribution rates for the sample as a whole and across groups, along with $p$ values from $F$-tests of equality of means across groups. Overall, the contribution rate was $1.11 \%$ (column 1), which was close to the expectation of the campaign (they expected a contribution rate of about $1 \%$ ex ante). This table suggests our first main result as follows.

Finding 1. The use of social information and a reference point increased the likelihood of contributing. The contribution rate in the competitive treatment was $85 \%$ higher than that of the control treatment $(p=.01)$, and $34 \%$ higher than the cooperative treatment $(p=.16)$. The cooperative treatment induced a 38\% higher contribution rate than the control, although not significantly so $(p=.24)$.

While this first finding suggests that the competitive treatment led to a greater effect on the extensive margin than the control, the effect of the cooperative treatment is less clear despite economically large differences in contribution rates. Unfortunately, the sample size in our study was limited by the total number of potential contributors in this race, a problem inherent in the use of mail solicitations to study competing fund raising strategies.

Owing to the slight imbalance across groups in some baseline observable characteristics, a preferred model may be one which controls for these variables. Table 3, columns 1 and 2, present estimates from Probit models estimating relative probabilities of contributing, with and without controlling for pretreatment demographics; perhaps not surprisingly, these models give similar results to the comparison in means. ${ }^{9}$ Table 3 also demonstrates that older recipients are more likely to contribute to our Democratic candidate, while registered Republicans (relative to registered Democrats) and Black recipients (relative to White recipients) are less likely to contribute.

\section{B. Contribution Distribution}

Our second main result concerns the intensive margin of contributing. The second and third rows of Table 2 compare mean contribution amounts, for both the entire sample and for the sample of those who actually contributed. For the sample as a whole (column 1), the mean contribution is $\$ 0.70$, while the mean contribution conditional on donating is $\$ 63.10$. Note that while the unconditional mean contribution is marginally different between the

9. These results are robust to the "rare event bias" described in King and Zeng (2001), a bias arising in discrete dependent variable models when the event (a contribution, in our case) is observed a relatively low percentage of the time. 
TABLE 3

Contribution Rates and Amounts, Controlling for Pretreatment Observables

\begin{tabular}{|c|c|c|c|c|}
\hline $\begin{array}{l}\text { Estimation Method } \\
\text { Outcome }\end{array}$ & $\begin{array}{c}\text { Probit } \\
\text { Contributed } \\
\text { (1) }\end{array}$ & $\begin{array}{c}\text { Probit } \\
\text { Contributed } \\
\text { (2) }\end{array}$ & $\begin{array}{c}\text { OLS } \\
\text { Contribution } \\
\text { Amount (\$) } \\
\text { (3) }\end{array}$ & $\begin{array}{c}\text { OLS } \\
\text { Contribution } \\
\text { Amount (\$) } \\
\text { (4) }\end{array}$ \\
\hline Cooperative treatment & $\begin{array}{c}0.004 \\
(0.003)\end{array}$ & $\begin{array}{c}0.003 \\
(0.003)\end{array}$ & $\begin{array}{c}0.076 \\
(0.227)\end{array}$ & $\begin{array}{c}0.073 \\
(0.227)\end{array}$ \\
\hline Competitive treatment & $\begin{array}{c}0.007 * * \\
(0.003)\end{array}$ & $\begin{array}{c}0.006 * * \\
(0.003)\end{array}$ & $\begin{array}{l}0.432 * \\
(0.227)\end{array}$ & $\begin{array}{l}0.423 * \\
(0.227)\end{array}$ \\
\hline Male & & $\begin{array}{c}-0.0003 \\
(0.002)\end{array}$ & & $\begin{array}{c}0.059 \\
(0.201)\end{array}$ \\
\hline Age & & $\begin{array}{c}0.0002 * * \\
(-0.00007)\end{array}$ & & $\begin{array}{c}0.004 \\
(0.007)\end{array}$ \\
\hline Registered Republican & & $\begin{array}{c}-0.006 * * * \\
(0.002)\end{array}$ & & $\begin{array}{l}-0.505 \\
(0.427)\end{array}$ \\
\hline Registered with other party & & $\begin{array}{c}0.012 \\
(0.010)\end{array}$ & & $\begin{array}{c}0.604 \\
(1.062)\end{array}$ \\
\hline Registered with no party & & $\begin{array}{l}-0.004 \\
(0.005)\end{array}$ & & $\begin{array}{l}-0.296 \\
(0.651)\end{array}$ \\
\hline Voted in a primary & & $\begin{array}{c}0.009 \\
(0.006)\end{array}$ & & $\begin{array}{c}0.641 \\
(0.439)\end{array}$ \\
\hline Lives outside the district & & $\begin{array}{c}0.008 \\
(0.008)\end{array}$ & & $\begin{array}{c}0.368 \\
(0.467)\end{array}$ \\
\hline Black & & $\begin{array}{c}-0.009 * * * \\
(0.002)\end{array}$ & & $\begin{array}{c}-0.808^{* *} \\
(0.322)\end{array}$ \\
\hline Other race & & $\begin{array}{l}-0.001 \\
(0.004)\end{array}$ & & $\begin{array}{l}-0.448 \\
(0.463)\end{array}$ \\
\hline Indicator for missing demographics & & Yes & & Yes \\
\hline $\begin{array}{l}\text { Observations } \\
\text { Log likelihood }\end{array}$ & $\begin{array}{c}9,954 \\
-601.62\end{array}$ & $\begin{array}{c}9,954 \\
-58083\end{array}$ & 9,954 & 9,954 \\
\hline $\begin{array}{l}R^{2} \\
\mathrm{H}_{0}: \text { Cooperative treatment } \\
\text { Competitive treatment, } p \text { value }\end{array}$ & .19 & .16 & $\begin{array}{c}0.0004 \\
.12\end{array}$ & $\begin{array}{c}0.0019 \\
.12\end{array}$ \\
\hline
\end{tabular}

Notes: Columns 1 and 2 contain estimated marginal effects from probit models; standard errors in parentheses. Columns 3 and 4 contain estimated coefficients from ordinary least squares (OLS) regressions; standard errors in parentheses. All donor characteristics were obtained from Florida's public-record voter files and were self-reported when the recipient registred to vote. A voter is defined as having voted in a primary if they voted in any primary election between the years of 1996 and 2008 . The omitted categories are "Control treatment," "Registered Democrat," and "White."

$* * * p<.01 ; * * p<.05 ; * p<0.1$.

control and competitive treatment $(p=.13)$, this difference is largely driven by the differential contribution rates; upon conditioning on a strictly positive contribution, mean contribution amounts are indistinguishable across all groups. We again test for the robustness of this comparison in means by controlling for all observable individual characteristics in a regression setting. Columns 3 and 4 in Table 3 show that treatment effects are virtually unchanged by the slight baseline differences in observables.

Average contribution amounts, however, mask important and significant differences in the distributions of conditional contributions across treatments. This can be seen in Figure 2, which plots the distribution of strictly positive contribution amounts in each group. In order to see these differences more clearly, we subtract the histograms of contribution amounts for each treatment group from the distribution under the control, and plot in Figure 3 these "differenced" distributions. Specifically, panel A of Figure 3 contains the difference between the distribution of contributions under the cooperative treatment less the control, while panel B contains this difference of contributions under the cooperative group less the control. (Note that we remove contributions over $\$ 100$-representing 6\% of contributions - for visual ease.) The randomized assignment of treatment allows us to interpret these histograms as the "additional" effect of the cooperative and competitive treatments above the control.

The majority of additional contributions in the cooperative treatment (panel A) appear to be centered in the $\$ 20$ to $\$ 30$ range; for example, Panel A shows that there were four "extra" contributions of $\$ 20$, two of $\$ 25$, one of $\$ 28$, and 


\section{FIGURE 2}

Histograms of the Nonzero Contribution Amounts for the Control, Cooperative Treatment, and Competitive Treatment Groups

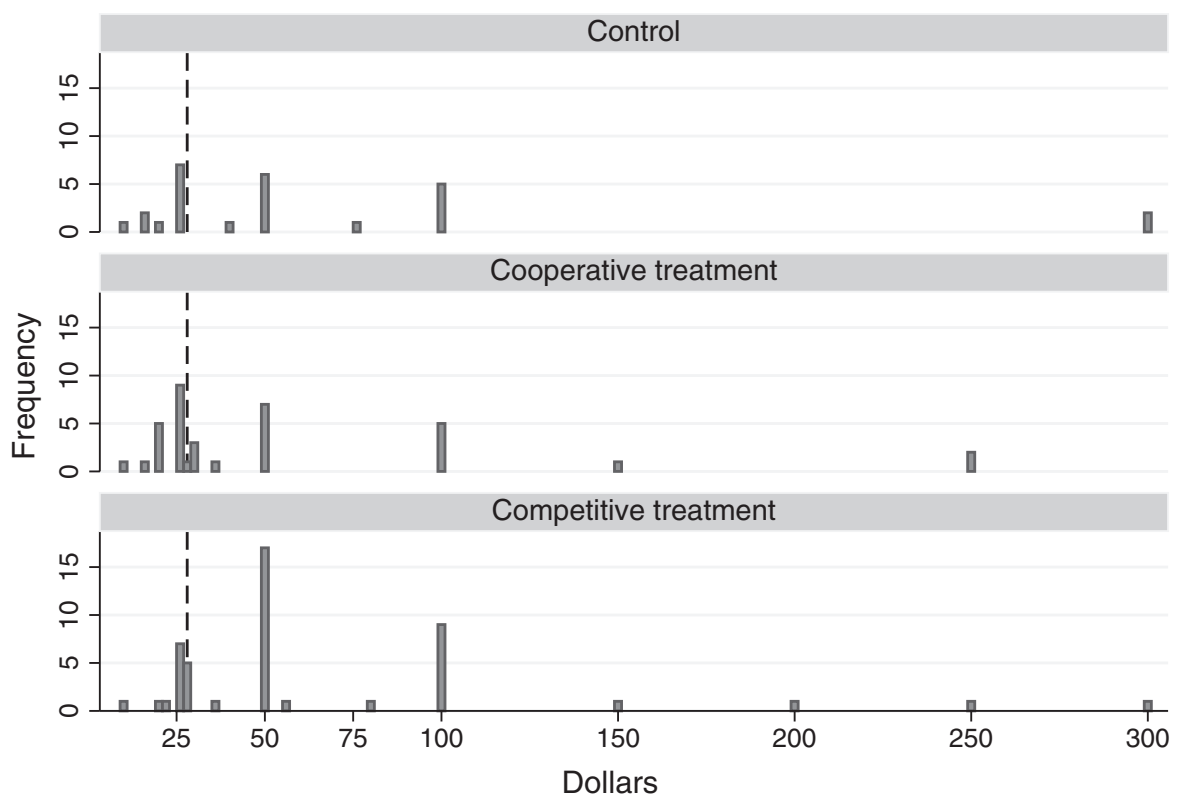

three of \$30. Panel B shows that there were multiple "additional" contributions in the competitive treatment at $\$ 28, \$ 50$, and $\$ 100$ compared to the control, with the majority (11 contributions) located at $\$ 50$. Qualitatively, the common reference point of $\$ 28$ in the cooperative and competitive treatments appears to have induced different contribution behavior depending on the context. The cooperative treatment induced a large concentration of contributions in the \$20 to $\$ 30$ range, while the competitive treatment induced an even larger number of $\$ 50$ contributions, close to twice the reference amount. ${ }^{10}$ Note that the reference point had an absolute effect as well, in that there are numerous contributions of

10. The probabilities of contributing between $\$ 20$ and $\$ 30$, conditional on contributing, are $29.2 \%, 50.0 \%$, and $30.8 \%$ for the competitive, cooperative, and control groups, respectively. The probabilities of contributing $\$ 50$, conditional on contributing, are $35.4 \%, 19.4 \%$, and $23.1 \%$ for the competitive, cooperative, and control groups, respectively. Given the ex post determination of these contribution bins, we are reluctant to draw strong conclusions. However, we note that the rate of contributing \$20 to $\$ 30$ is statistically greater in the cooperative group compared to the competitive group $(p=.05)$ and marginally greater than the control $(p=.13)$, while the rate of contributing $\$ 50$ is marginally greater in the competitive group compared to the cooperative group $(p=.11)$.
\$28 from competitive and cooperative subjects and none from control subjects.

Figure 4 compares the cumulative distribution functions of contribution amounts in the cooperative and competitive treatments where, again for visual ease, we truncate the distribution above $\$ 100$. The contribution distribution from the competitive treatment first order stochastically dominates the distribution from the competitive treatment in this region (one contribution of $\$ 200$ breaks this relationship in contributions higher than \$100). The $p$ value from the Kolmogorov-Smirnov test of the equality of these distributions is .10 (this test does not exclude contributions above \$100). ${ }^{11}$

These observations lead to our second main result:

Finding 2. The distribution of contributions of the competitive group first order stochastically dominates that of the competitive group for the vast majority of the distribution. It appears that the cooperative treatment induces more contributions than the competitive treatment in the

11. The cooperative and competitive distributions are not significantly different from the control (not shown) with Kolmogorov-Smirnov $p$ values of .76 and .32, respectively. 
FIGURE 3

Differences in the Distributions of Strictly Positive Contribution Amounts Between Each Treatment Group and the Control
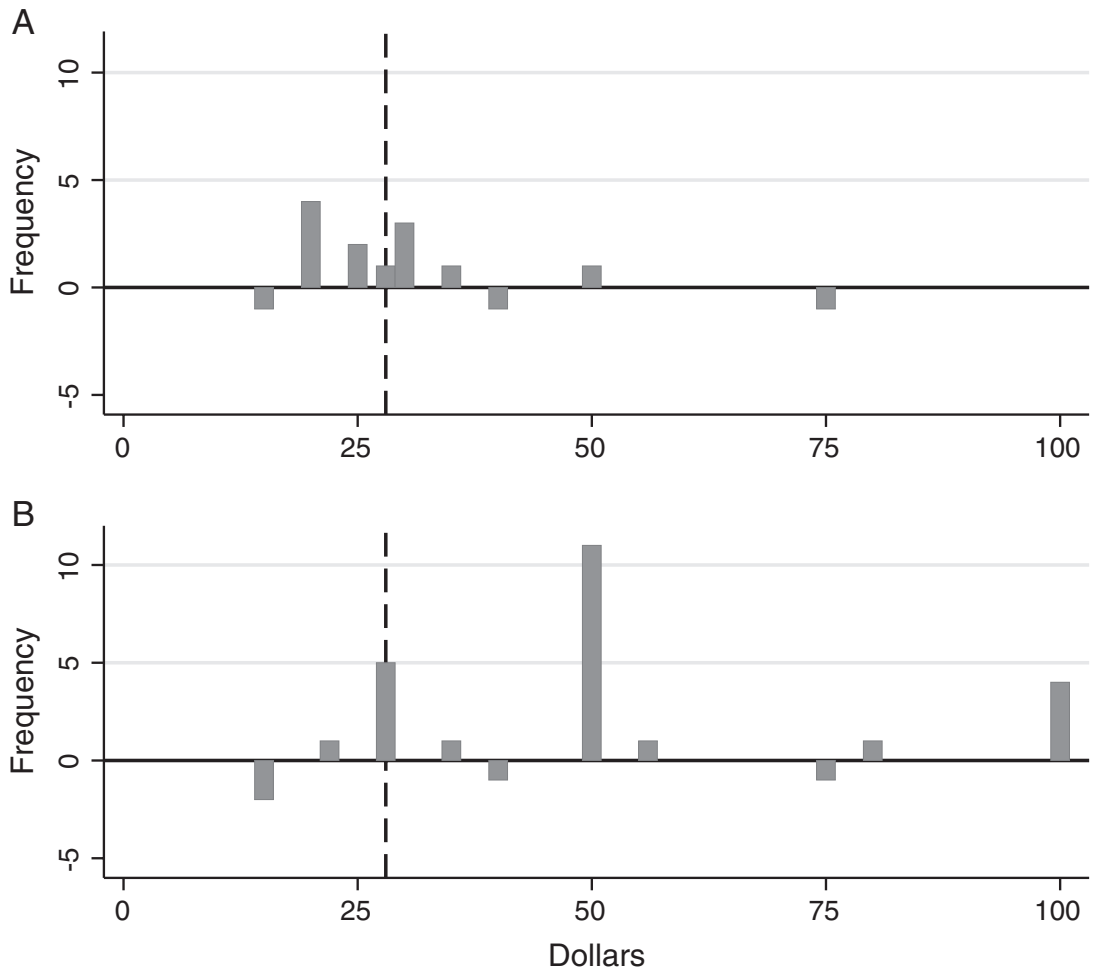

Panel A: The cooperative treatment minus the control. Panel B: The competitive treatment minus the control. Note: Samples in both panels exclude contributions greater than $\$ 100$.

range near the reference point $(\$ 20-\$ 30)$, while the competitive treatment induces more contributions than the cooperative treatment at close to twice the reference point $(\$ 50)$.

\section{DISCUSSION AND CONCLUSION}

We present the results of a field experiment in which potential donors were motivated to contribute by either a competitive or a cooperative signal. Specifically, solicitation postcards to political donors contained either information about recent contributions of those in the same political group (a cooperative message) or the opposing political group (a competitive message), or no information about past contributions (a control message). The competitive message induced a significantly higher contribution than the control. The distribution of contributions in the competitive treatment (nearly) first order stochastically dominates that of the cooperative treatment. It appears that, while members of the cooperative group were more likely to contribute around the stated reference point of their peers, the members of the competitive group were more likely to contribute an amount of nearly twice the stated reference point. This is the first natural field experiment to study the effects of competitive and cooperative motivations in a public good contributing environment, and importantly, our results confirm those found in the laboratory (Bornstein and Ben-Yossef 1994; Bornstein, Gneezy, and Nagel 2002).

We develop a theoretical model of our field environment to demonstrate how competitive and cooperative "signals" can induce a socially minded individual to differentially contribute to a public good. The model predicts that the effect of the cooperative treatment is dependent on the individual's form of social preferences: 


\section{FIGURE 4}

Cumulative Distribution Functions of Nonzero Contribution Amounts for the Cooperative and Competitive Treatments

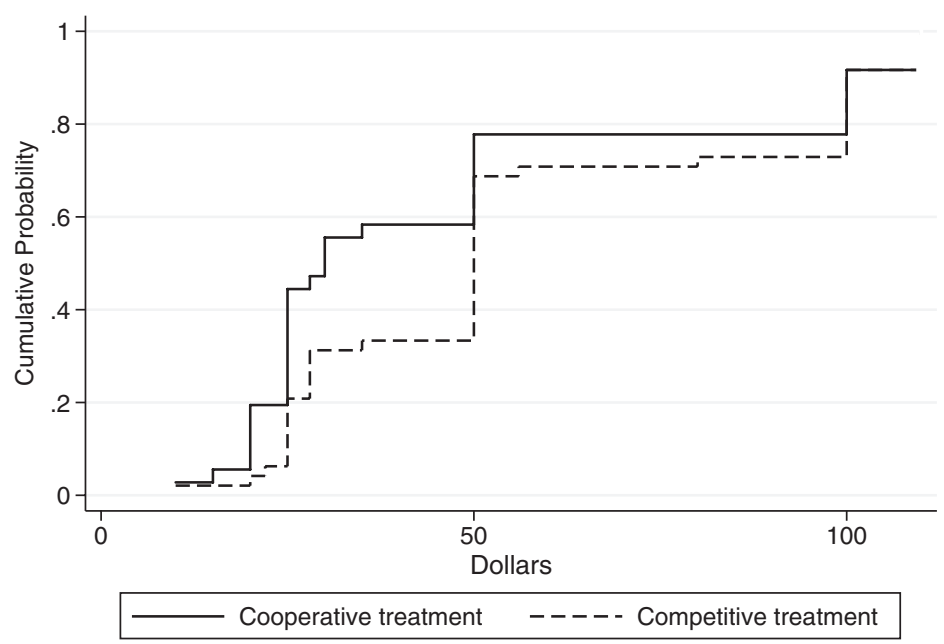

Note: Sample is truncated above contributions of $\$ 100$.

people with preferences to increase social welfare (even at a cost to themselves) will contribute more when observing the cooperative message than the control message, while people with preferences for inequity aversion will contribute closer to the contributions of others (the stated reference point). The effect of the competitive treatment depends on the individual's preferences for negative reciprocity: if a person is willing to reduce his/her own payoff to lower the payoff of a "misbehaving" player, he/she will contribute more when observing the competitive treatment.

The framework in our study - contributions amongst competing groups - is present in many other contexts. For example, consider hunters and hikers contributing to, respectively, the National Rifle Association (NRA) and the Sierra Club, two organizations with competing aims for the use of public lands. Similarly, consider Jewishand Arab-Americans contributing to their respective lobbying groups dedicated to influencing U.S. policy on Israel and Palestine. Our findings suggest that both organizations in these environments may find it profitable to invoke competitive motivations for potential contributors with strong feelings of negative reciprocity toward the competing group members, while invoking cooperative motivations for potential contributors that demonstrate strong social welfare preferences or potential contributors who are expected to contribute small amounts but demonstrate strong feelings of inequity aversion.

\section{APPENDIX}

Proofs

First, we will write out the full payoff of utility for each treatment, collecting terms as necessary:

$$
\begin{aligned}
& U_{3}^{\text {cont }}=w \cdot P\left(c_{1}-c_{2}+c_{3}\right)-c_{3} \\
& U_{3}^{\text {coop }} \quad w \cdot P\left(c_{1}-c_{2}+c_{3}\right)-(1-\rho) c_{3}-\rho c_{1} \quad \text { if } \pi_{3} \leq \pi_{1} \\
& U_{3}^{\text {coop }}={ }_{w} \cdot P\left(c_{1}-c_{2}+c_{3}\right)-(1-\sigma) c_{3}-\sigma c_{1} \quad \text { if } \pi_{3} \leq \pi_{1} \\
& w \cdot P\left(c_{1}-c_{2}+c_{3}\right)(1-2 \rho+2 \theta)-c_{3} \quad \text { if } \pi_{3}>\pi_{2} \\
& U_{3}^{\text {comp }}=\begin{array}{c}
(1-\rho+\theta)+(\rho-\theta)\left(w-c_{2}\right) \\
w \cdot P\left(c_{1}-c_{2}+c_{3}\right)(1-2 \sigma+2 \theta)-c_{3} \quad \text { if } \pi_{3} \leq \pi_{2}
\end{array} \\
& (1-\sigma+\theta)+(\sigma-\theta)\left(w-c_{2}\right)
\end{aligned}
$$

Taking derivatives and second derivatives with respect to $c_{3}$ yields:

$$
\begin{aligned}
& \partial U_{3}^{\text {cont }} / \partial c_{3}=w \cdot P^{\prime}\left(c_{1}-c_{2}+c_{3}\right)-1 \\
& \begin{array}{ll}
w \cdot P^{\prime}\left(c_{1}-c_{2}+c_{3}\right)-(1-\rho) & \text { if } \pi_{3}>\pi_{1} \\
\partial U_{3}^{\text {coop }} / \partial c_{3}=w \cdot P^{\prime}\left(c_{1}-c_{2}+c_{3}\right)-(1-\sigma) & \text { if } \pi_{3} \leq \pi_{1}
\end{array} \\
& \partial U_{3}^{\mathrm{comp}} / \partial c_{3}=\begin{array}{ll}
w \cdot P^{\prime}\left(c_{1}-c_{2}+c_{3}\right)(1-2 \rho+2 \theta) & \text { if } \pi_{3}>\pi_{2} \\
w \cdot P^{\prime}\left(c_{1}-c_{2}+c_{3}\right)(1-2 \sigma+2 \theta) & \text { if } \pi_{3} \leq \pi_{2}
\end{array} \\
& -(1-\sigma+\theta) \\
& \partial^{2} U_{3}^{\text {cont }} / \partial c_{3}^{2}=w \cdot P^{\prime \prime}\left(c_{1}-c_{2}+c_{3}\right) \\
& w \cdot P^{\prime \prime}\left(c_{1}-c_{2}+c_{3}\right) \quad \text { if } \pi_{3}>\pi_{1} \\
& \partial^{2} U_{3}^{\text {coop }} / \partial c_{3}^{2}=w \cdot P^{\prime \prime}\left(c_{1}-c_{2}+c_{3}\right) \quad \text { if } \pi_{3} \leq \pi_{1} \\
& w \cdot P^{\prime \prime}\left(c_{1}-c_{2}+c_{3}\right)(1-2 \rho+2 \theta) \text { if } \pi_{3}>\pi_{2} \\
& \partial^{2} U_{3}^{\mathrm{comp}} / \partial c_{3}^{2}=w \cdot P^{\prime \prime}\left(c_{1}-c_{2}+c_{3}\right)(1-2 \sigma+2 \theta) \text { if } \pi_{3} \leq \pi_{2}
\end{aligned}
$$


When focusing on the cooperative utility function $U_{3}^{\text {coop }}$, we note that $\pi_{3}>\pi_{1} \Longleftrightarrow c_{3}<c_{1}$. The next Lemma describes the shape of these functions and the location of potential maxima. Recall that $c_{3}^{\text {cont }}, c_{3}^{\text {coop }}$, and $c_{3}^{\text {comp }}$ are defined as the solutions to $U_{3}^{\text {cont }}, U_{3}^{\text {coop }}$, and $U_{3}^{\text {comp }}$. Recall the assumption that, for some $x, P^{\prime \prime}(\Delta c)>0$ for all $\Delta c<x$ and $P^{\prime \prime}(\Delta c)<0$ for all $\Delta c>x$. Finally, for notational ease, define a treatment indicator $t \in\{$ cont, comp, coop $\}$.

LEMMA 1. For each function $U_{3}^{t}$, there is at most one point such that $U_{3}^{t},\left(c_{3}\right)=0$ such that $c_{3}>x-c_{1}+c_{2}$. If this point exists, denote it $\widetilde{c}_{3}^{t}$.

\section{Then:}

(i) $c_{3}^{\text {cont }} \in\left\{0, \widetilde{c}_{3}^{\text {cont }}\right\}$,

(ii) $c_{3}^{\text {coop }} \in\left\{0, \widetilde{c}_{3}^{\text {coop }}, c_{1}\right\}$

(iii) $c_{3}^{\text {comp }} \in\left\{0, \widetilde{c}_{3}^{\text {comp }}, c_{2}\right\}$

Furthermore, $c_{3}^{\text {coop }}=c_{1}$ requires that $\partial U_{3}^{\text {coop }} / \partial c_{3} \geq 0$ as $c_{3} \rightarrow c_{1}$ from below and $\partial U_{3}^{\mathrm{coop}} / \partial c_{3} \leq 0$ as $c_{3} \rightarrow c_{1}$ from above.

Furthermore, $c_{3}^{\text {coop }}=c_{2}$ requires that $\partial U_{3}^{\mathrm{comp}} / \partial c_{3} \geq 0$ as $c_{3} \rightarrow c_{2}$ from below and $\partial U_{3}^{\mathrm{comp}} / \partial c_{3} \leq 0$ as $c_{3} \rightarrow c_{2}$ from above.

\section{Proof of Lemma 1}

Note that each $U_{3}^{t}$ is continuous except for $U_{3}^{\text {coop }}$ when $c_{3}=c_{1}$ and $U_{3}^{\text {comp }}$ when $c_{3}=c_{2}$. Therefore, the maximum must occur at either 0 , the point of discontinuity, points where the derivative equals 0 , or be undefined (if $U_{3}^{t}$ was rising as $c_{3} \rightarrow \infty$ ).

First, note that as $c_{3} \rightarrow \infty, U_{3} \rightarrow-\infty$ and therefore the maximum is not undefined.

We will now show that there is only one potential point at which the derivative equals 0 that can be a potential maximum, and that point must be greater than $x-c_{1}+c_{2}$.

Note that each $U_{3}^{t}$ is not necessarily a concave function for each treatment. In fact, we will show that $U_{3}^{t}$ is potentially convex before it is concave. To see this, consider the second derivative of the utility function in each treatment. Recall the assumption that, for some $x$, $P^{\prime \prime}(\Delta c)>0$ for all $\Delta c<x$ and $P^{\prime \prime}(\Delta c)<0$ for all $\Delta c>x$. This implies that $P^{\prime \prime}\left(c_{1}-c_{2}+c_{3}\right)>0$ for all $c_{3}<x-c_{1}+c_{2}$ and $P^{\prime \prime}\left(c_{1}-c_{2}+c_{3}\right)<0$ for all $c_{3}>x-c_{1}+c_{2}$. Adding a positive multiplier, we get: $w \cdot P^{\prime \prime}\left(c_{1}-c_{2}+c_{3}\right)>0$ for all $c_{3}<x-c_{1}+c_{2}$ and $w \cdot P^{\prime \prime}\left(c_{1}-c_{2}+c_{3}\right)<0$ for all $c_{3}>x-c_{1}+c_{2}$. Similarly, for a different positive multiplier, we get: $w \cdot P^{\prime \prime}\left(c_{1}-c_{2}+c_{3}\right)(1-2 \rho+2 \theta)>0$ and $w \cdot P^{\prime \prime}\left(c_{1}-c_{2}+c_{3}\right)(1-2 \sigma+2 \theta)>0$ for all $c_{3}<x-c_{1}+c_{2}$ and $w \cdot P^{\prime \prime}\left(c_{1}-c_{2}+c_{3}\right)(1-2 \rho+2 \theta)<0$ and $w \cdot P^{\prime \prime}\left(c_{1}-c_{2}+c_{3}\right)(1-2 \sigma+2 \theta)<0$ for all $c_{3}>x-c_{1}+c_{2}$ as $(1-2 \rho+2 \theta)>0$ and $(1-2 \sigma+2 \theta)>0$ given that $\sigma<\rho<1$. Therefore, $\partial^{2} U_{3}^{\text {cont }} / \partial c_{3}^{2}>0$ and $\partial^{2} U_{3}^{\text {coop }} / \partial c_{3}^{2}>0$ and $\partial^{2} U_{3}^{\text {comp }} / \partial c_{3}^{2}>0$ for all $c_{3}<x-c_{1}+c_{2}$ and $\partial^{2} U_{3}^{\text {cont }} / \partial c_{3}^{2}<0$ and $\partial^{2} U_{3}^{\text {coop }} / \partial c_{3}^{2}<0$ and $\partial^{2} U_{3}^{\text {comp }} / \partial c_{3}^{2}<0$ for all $c_{3}>x-c_{1}+c_{2}$. That is, each $U_{3}^{t^{3}}$ is potentially strictly convex (if $c_{2}-c_{1}<x$ ) and then strictly concave. There is one potential point in the interior of the strictly convex portion of each $U_{3}^{t}$ (when $c_{3} \in\left(0, x-c_{1}+c_{2}\right)$ ) at which the derivative equals 0 . As the function is convex at this point, this is not a global maximum. There is one potential point in the interior of the strictly concave portion of each $U_{3}^{t}$ (when $c_{3}>x-c_{1}+c_{2}$ ) at which the derivative equals 0 . As the function is concave at this point, this is a potential global maximum. If it exists, denote this point $\widetilde{c}_{3}^{t}$ for a given treatment $t$.
Therefore, the maximum must occur at either 0 , the point of discontinuity, or $\widetilde{c}_{3}^{t}$.

Finally, note that if the maximum occurs at a discontinuity, the relations at the bottom of the Lemma must be satisfied. Focusing on $U_{3}^{\text {comp }}$ : If $\partial U_{3}^{\text {comp }} / \partial c_{3}<0$ as $c_{3} \rightarrow c_{2}$ from below, then there exists some $\epsilon>0$ such that $U_{3}^{\text {comp }}\left(c_{2}-\epsilon\right)>U_{3}^{\text {comp }}\left(c_{2}\right)$ and $c_{2}$ is not a maximum; if $\partial U_{3}^{\text {comp }} / \partial c_{3}>0$ as $c_{3} \rightarrow c_{2}$ from above, then there exists some $\epsilon>0$ such that $U_{3}^{\text {comp }}\left(c_{2}+\epsilon\right)>U_{3}^{\text {comp }}\left(c_{2}\right)$ and $c_{2}$ is not a maximum. The same logic holds for $U_{3}^{\text {coop }}$.

LEMMA 2a. If $\sigma>0$, then $c_{3}^{\text {cont }}>0$ implies that $c_{3}^{\text {coop }}>0$.

Proof of Lemma $2 a$

If the solution to $U_{3}^{\text {cont }}$ is interior, then $U_{3}^{\text {cont }}\left(c_{3}^{\text {cont }}\right)-$ $U_{3}^{\text {cont }}(0) \geq 0$.

That is: $w \cdot P\left(c_{1}-c_{2}+c_{3}^{\text {cont }}\right)-c_{3}^{\text {cont }}-w \cdot P\left(c_{1}-c_{2}\right)$ $\geq 0$

Consider $U_{3}^{\text {coop }}\left(c_{3}^{\text {cont }}\right)-U_{3}^{\text {coop }}(0)$. This is equal to:

$$
\begin{aligned}
& w \cdot P\left(c_{1}-c_{2}+c_{3}^{\text {cont }}\right)-w \cdot P \\
& U_{3}^{\text {coop }}\left(c_{3}^{\text {cont }}\right)\left(c_{1}-c_{2}\right)-(1-\rho) c_{3}^{\text {cont }} \quad \text { if } \pi_{3}>\pi_{1} \\
& -U_{3}^{\text {coop }}(0)=\begin{array}{ll}
w \cdot P\left(c_{1}-c_{2}+c_{3}^{\text {cont }}\right)-w \cdot P & \text { if } \pi_{3} \leq \pi_{1} \\
\left(c_{1}-c_{2}\right)-(1-\sigma) c_{3}^{\text {cont }} &
\end{array}
\end{aligned}
$$

As $\rho \in[0,1]$, then $(1-\rho) c_{3}^{\text {cont }} \leq c_{3}^{\text {cont }}$. Similarly, as $\sigma \in[0, \rho],(1-\sigma) c_{3}^{\text {cont }} \leq c_{3}^{\text {cont }}$.

But, $\quad w \cdot P\left(c_{1}-c_{2}+c_{3}^{\text {cont }}\right)-w \cdot P\left(c_{1}-c_{2}\right)-$ $(1-\rho) c_{3}^{\text {cont }} \geq 0 \quad$ and $\quad w \cdot P\left(c_{1}-c_{2}+c_{3}^{\text {cont }}\right)-w$. $P\left(c_{1}-c_{2}\right)-(1-\sigma) c_{3}^{\text {cont }} \geq 0$ as $w \cdot P\left(c_{1}-c_{2}+c_{3}^{\text {cont }}\right)-$ $c_{3}^{\text {cont }}-w \cdot P\left(c_{1}-c_{2}\right) \geq 0$ (from above).

Therefore, $U_{3}^{\text {coop }}\left(c_{3}^{\text {cont }}\right)-U_{3}^{\text {coop }}(0) \geq 0$.

Note that $U_{3}^{\text {coop }}\left(c_{3}^{\text {coop }}\right) \geq U_{3}^{\text {coop }}\left(c_{3}^{\text {cont }}\right)$ as $c_{3}^{\text {coop }}$ maximizes $U_{3}^{\text {coop }}$.

Therefore $U_{3}^{\text {coop }}\left(c_{3}^{\text {coop }}\right)-U_{3}^{\text {coop }}(0) \geq 0$ and the maximum to $U_{3}^{\text {coop }}$ must be interior.

LEMMA 2b. If $\sigma>0$, then $\widetilde{c}_{3}^{\text {cont }}>c_{1}$ implies that $c_{3}^{\text {coop }} \neq$ $c_{1}$.

\section{Proof of Lemma $2 b$}

If $\widetilde{c}_{3}^{\text {cont }}>c_{1}$, then $U_{3}^{\text {cont }}\left(\widetilde{c}_{3}^{\text {cont }}\right)-U_{3}^{\text {cont }}\left(c_{1}\right) \geq 0$. That is: $w \cdot P\left(c_{1}-c_{2}+c_{3}^{\text {cont }}\right)-w \cdot P\left(c_{1}-c_{2}+c_{1}\right)-$ $\left(c_{3}^{\text {cont }}+c_{1}\right) \geq 0$.

Consider $U_{3}^{\text {coop }}\left(\widetilde{c}_{3}^{\text {cont }}\right)-U_{3}^{\text {coop }}\left(c_{1}\right)$. This is equal to: $\quad w \cdot P\left(c_{1}-c_{2}+\widetilde{c}_{3}^{\text {cont }}\right)-w \cdot P\left(c_{1}-c_{2}+c_{1}\right)-(1-\sigma)$ $\left(\widetilde{c}_{3}^{\text {cont }}+c_{1}\right)$ as $\widetilde{c}_{3}^{\text {cont }}>c_{1}$. As $\sigma \in[0,1],(1-\sigma)\left(\widetilde{c}_{3}^{\text {cont }}+c_{1}\right) \leq$ $\left(\widetilde{c}_{3}^{\text {cont }}+c_{1}\right)$. But then $w \cdot P\left(c_{1}-c_{2}+\widetilde{c}_{3}^{\text {cont }}\right)-w$. $P\left(c_{1}-c_{2}+c_{1}\right)-(1-\sigma)\left(\widetilde{c}_{3}^{\text {cont }}+c_{1}\right) \geq 0$ as $w \cdot P$ $\left(c_{1}-c_{2}+c_{3}^{\text {cont }}\right)-w \cdot P\left(c_{1}-c_{2}+c_{1}\right)-\left(c_{3}^{\text {cont }}+c_{1}\right) \geq 0$

(from above). Therefore, $U_{3}^{\text {coop }}\left(\widetilde{c}_{3}^{\text {cont }}\right)-U_{3}^{\text {coop }}\left(c_{1}\right) \geq 0$. Note that $U_{3}^{\text {coop }}\left(c_{3}^{\text {coop }}\right) \geq U_{3}^{\text {coop }}\left(\widetilde{c}_{3}^{\text {cont }}\right)$ as $c_{3}^{\text {coop }}$ maximizes $U_{3}^{\text {coop }}$. Therefore $U_{3}^{\text {coop }}\left(c_{3}^{\text {coop }}\right)-U_{3}^{\text {coop }}\left(c_{1}\right) \geq 0$ and the maximum to $U_{3}^{\text {coop }}$ cannot equal $c_{1}$.

LEMMA 3a. If $\theta>\rho$, then $c_{3}^{\text {cont }}>0$ implies that $c_{3}^{\text {comp }}>0$

Proof of Lemma $3 a$

If the solution to $U_{3}^{\text {cont }}$ is interior, then $U_{3}^{\text {cont }}\left(c_{3}^{\text {cont }}\right)$ $-U_{3}^{\text {cont }}(0)>0$. That is: $w \cdot P\left(c_{1}-c_{2}+c_{3}^{\text {cont }}\right)-c_{3}^{\text {cont }}-w$. $P\left(c_{1}-c_{2}\right)>0$.

Consider $U_{3}^{\text {comp }}\left(c_{3}^{\text {cont }}\right)-U_{3}^{\text {comp }}(0)$. This is equal to: 


$$
U_{3}^{\text {comp }}\left(c_{3}^{\text {cont }}\right)-U_{3}^{\text {coop }}(0)=
$$

$(1-\rho+\theta)\left(w \cdot P\left(c_{1}-c_{2}+c_{3}^{\text {cont }}\right)-c_{3}^{\text {cont }}-w \cdot P\right.$

$\left.\left(c_{1}-c_{2}\right)\right)+(\theta-\rho)\left(w \cdot P\left(c_{1}-c_{2}+c_{3}^{\text {cont }}\right)-w \cdot P\right.$

$\left.\left(c_{1}-c_{2}\right)\right)$ if $\pi_{3}>\pi_{2}$ and $(1-\sigma+\theta)\left(w \cdot P\left(c_{1}-c_{2}+c_{3}^{\text {cont }}\right)\right.$ $\left.-c_{3}^{\text {cont }}-w \cdot P\left(c_{1}-c_{2}\right)\right)+(\theta-\sigma)\left(w \cdot P\left(c_{1}-c_{2}+c_{3}^{\text {cont }}\right)-\right.$ $\left.w \cdot P\left(c_{1}-c_{2}\right)\right)$ if $\pi_{3} \leq \pi_{2}$

As $w \cdot P\left(c_{1}-c_{2}+c_{3}^{\text {cont }}\right)-c_{3}^{\text {cont }}-w \cdot P\left(c_{1}-c_{2}\right)>0$ and $\theta-\rho>0$ (which implies $\theta-\sigma>0$ as $\sigma<\rho$ ), then $(1-\rho+\theta)\left(w \cdot P\left(c_{1}-c_{2}+c_{3}^{\text {cont }}\right)-c_{3}^{\text {cont }}-w \cdot P\left(c_{1}-c_{2}\right)\right)$ $>0$ and $(1-\sigma+\theta)\left(w \cdot P\left(c_{1}-c_{2}+c_{3}^{\text {cont }}\right)-c_{3}^{\text {cont }}-\right.$ $\left.w \cdot P\left(c_{1}-c_{2}\right)\right)>0$. Furthermore, $(\theta-\rho)\left(w \cdot P\left(c_{1}-c_{2}\right.\right.$ $\left.\left.+c_{3}^{\text {cont }}\right)-w \cdot P\left(c_{1}-c_{2}\right)\right)>0$ and $(\theta-\sigma)\left(w \cdot P\left(c_{1}-c_{2}\right.\right.$ $\left.\left.+c_{3}^{\text {cont }}\right)-w \cdot P\left(c_{1}-c_{2}\right)\right)>0$. Therefore, $U_{3}^{\text {comp }}\left(c_{3}^{\text {cont }}\right)-$ $U_{3}^{\text {comp }}(0)>0$. Note that $U_{3}^{\text {comp }}\left(c_{3}^{\text {comp }}\right) \geq U_{3}^{\text {comp }}\left(c_{3}^{\text {cont }}\right)$ as $c_{3}^{\text {comp }}$ maximizes $U_{3}^{\text {comp }}$. Therefore $U_{3}^{\text {comp }}\left(c_{3}^{\text {comp }}\right)-$ $U_{3}^{\text {comp }}(0)>0$ the maximum to $U_{3}^{\text {comp }}$ must be interior.

LEMMA $3 \mathrm{~b}$. If $\theta>\rho$, then $\widetilde{c}_{3}^{\text {cont }}>c_{2}$ implies that $c_{3}^{\text {comp }} \neq$ $c_{2}$.

\section{Proof of Lemma $3 b$}

Recall that $\widetilde{c}_{3}^{\text {cont }}$ is the unique point such that $U_{3}^{\text {cont }},\left(c_{3}\right)=0$ in the strictly concave region of $U_{3}^{\text {cont }}$ when $c_{3}>x-c_{1}+c_{2}$. If $\widetilde{c}_{3}^{\text {cont }}>c_{2}$, then $U_{3}^{\text {cont }}\left(\widetilde{c}_{3}^{\text {cont }}\right)^{3}-$ $U_{3}^{\text {cont }}\left(c_{2}\right) \geq 0$. That is: $w \cdot P\left(c_{1}-c_{2}+c_{3}^{\text {cont }}\right)-w$. $P\left(c_{1}-c_{2}+c_{2}\right)-\left(c_{3}^{\text {cont }}+c_{2}\right) \geq 0$. Note also that, as $\widetilde{c}_{3}^{\text {cont }}>c_{2}, w \cdot P\left(c_{1}-c_{2}+\widetilde{c}_{3}^{\text {cont }}\right)-w \cdot P\left(c_{1}-c_{2}+c_{2}\right)>0$. Consider $U_{3}^{\text {comp }}\left(\widetilde{c}_{3}^{\text {cont }}\right)-U_{3}^{\text {comp }}\left(c_{1}\right)$. This is equal to:

$U_{3}^{\text {comp }}\left(\widetilde{c}_{3}^{\text {cont }}\right)-U_{3}^{\text {coop }}\left(c_{2}\right)=(1-\rho+\theta)\left(w \cdot P\left(c_{1}-\right.\right.$ $\left.\left.c_{2}+\widetilde{c}_{3}^{\text {cont }}\right)-\left(\widetilde{c}_{3}^{\text {cont }}+c_{2}\right)-w \cdot P\left(c_{1}-c_{2}+c_{2}\right)\right)+$

$(\theta-\rho)\left(w \cdot P\left(c_{1}-c_{2}+\widetilde{c}_{3}^{\text {cont }}\right)-w \cdot P\left(c_{1}-c_{2}+c_{2}\right)\right)$

if $\pi_{3}>\pi_{2}$ and $(1-\sigma+\theta)\left(w \cdot P\left(c_{1}-c_{2}+\widetilde{c}_{3}^{\text {cont }}\right)-\right.$ $\left.\left(\widetilde{c}_{3}^{\text {cont }}+c_{2}\right)-w \cdot P\left(c_{1}-c_{2}+c_{2}\right)\right)+(\theta-\sigma)\left(w \cdot P\left(c_{1}-\right.\right.$ $\left.\left.c_{2}+\widetilde{c}_{3}^{\text {cont }}\right)-w \cdot P\left(c_{1}-c_{2}+c_{2}\right)\right)$ if $\pi_{3} \leq \pi_{2}$

We have established that $w \cdot P\left(c_{1}-c_{2}+\widetilde{c}_{3}^{\text {cont }}\right)-$ $\left(\widetilde{c}_{3}^{\text {cont }}+c_{2}\right)-w \cdot P\left(c_{1}-c_{2}+c_{2}\right) \geq 0$ and $w \cdot P\left(c_{1}-c_{2}+\right.$ $\left.\widetilde{c}_{3}^{\text {cont }}\right)-w \cdot P\left(c_{1}-c_{2}+c_{2}\right)>0$. As $\theta>\rho>\sigma$ by assumption, the terms $(1-\rho+\theta),(1-\sigma+\theta),(\theta-\rho),(\theta-\sigma)$ must all be positive. Therefore, $U_{3}^{\text {comp }}\left(\widetilde{c}_{3}^{\text {cont }}\right)-U_{3}^{\text {coop }}\left(c_{2}\right)>0$. Therefore, $c_{2}$ cannot maximize $U_{3}^{\text {comp }}$ and so $c_{3}^{\text {comp }} \neq c_{2}$.

Now, we will prove each statement:

\section{Proof of Statement 1}

First, if $c_{3}^{\text {cont }}=0$, then $c_{3}^{\text {coop }} \geq c_{3}^{\text {cont }}$ as $c_{3}^{\text {coop }} \geq 0$ (contributions must be weakly positive).

Next, if $c_{3}^{\text {cont }}>0$, we will show that $c_{3}^{\text {coop }}>c_{3}^{\text {cont }}$. Now, given Lemma 1 , we know that $c_{3}^{\text {cont }}=\widetilde{c}_{3}^{\text {cont }}$ and $c_{3}^{\text {coop }} \in$ $\left\{0, \widetilde{c}_{3}^{\text {coop }}, c_{1}\right\}$. Note that Lemma 2 a implies that $c_{3}^{\text {coop }} \neq 0$. Therefore $c_{3}^{\text {coop }} \in\left\{\widetilde{c}_{3}^{\text {coop }}, c_{1}\right\}$.

Next, we will show that $\widetilde{c}_{3}^{\text {coop }}>\widetilde{c}_{3}^{\text {cont }}$. Recall that $\widetilde{c}_{3}^{\text {cont }}$ is the unique point such that $U_{3}^{\text {cont' }}\left(c_{3}\right)=0$ when $c_{3}>x-c_{1}+c_{2}$. That is, $\partial U_{3}^{\text {cont }} /\left.\partial c_{3}\right|_{c_{3}}$ cont $=$ $w \cdot P^{\prime}\left(c_{1}-c_{2}+c_{3}^{\text {cont }}\right)-1=0 \quad$ and $\quad \tilde{c}_{3}^{\text {cont }}>x-c_{1}+c_{2}$ must be true. Now, consider $\partial U_{3}^{\text {coop }} /\left.\partial c_{3}\right|_{\tau_{3} \text { cont }}=$ $\left\{w \cdot P^{\prime}\left(c_{1}-c_{2}+\widetilde{c}_{3}^{\text {cont }}\right)-1+\rho \quad\right.$ If $\widetilde{c}_{3}^{\text {cont }}<c_{1}$ $\left\{w \cdot P^{\prime}\left(c_{1}-c_{2}+\widetilde{c}_{3}^{\text {cont }}\right)-1+\sigma \quad\right.$ If $\widetilde{c}_{3}^{\text {cont }} \geq c_{1}$ recalling that $\pi_{3}>\pi_{1} \Longleftrightarrow c_{3}<c_{1}$. Given that $w \cdot P^{\prime}\left(c_{1}-c_{2}+\widetilde{c}_{3}^{\text {cont }}\right)-1=0, \quad \partial U_{3}^{\text {coop }} /\left.\partial c_{3}\right|_{c_{3} \text { cont }}=$ $\left\{\begin{array}{ll}\rho>0 & \text { if } \widetilde{c}_{3}^{\text {cont }}<c_{1} \\ \sigma>0 & \text { if } \widetilde{c}_{3}^{\text {cont }} \geq c_{1}\end{array}\right\} . \quad$ As $\quad \tilde{c}_{3}^{\text {cont }}>x-c_{1}+c_{2}$,
$U_{3}^{\text {coop }}$ must be concave at $\widetilde{c}_{3}^{\text {cont }}$ by Lemma 1 . Therefore, $\widetilde{c}_{3}^{\text {coop }}>\widetilde{c}_{3}^{\text {cont }}$.

We know that $c_{3}^{\text {coop }} \in\left\{\widetilde{c}_{3}^{\text {coop }}, c_{1}\right\}$ and $c_{3}^{\text {cont }}=\widetilde{c}_{3}^{\text {cont }}$ and $\widetilde{c}_{3}^{\text {coop }}>\widetilde{c}_{3}^{\text {cont }}$. If $\widetilde{c}_{3}^{\text {cont }}<c_{1}$, then $c_{3}^{\text {cont }}=\widetilde{c}_{3}^{\text {cont }}<$ $\left\{\widetilde{c}_{3}^{\text {coop }}, c_{1}\right\} c_{3}^{\text {coop }}$ If $\tilde{c}_{3}^{\text {cont }}>c_{1}$, Lemma $2 \mathrm{~b}$ proves that $c_{3}^{c o o p} \neq c_{1}$ and therefore $c_{3}^{\text {coop }}=\widetilde{c}_{3}^{\text {coop }}$, and therefore $c_{3}^{\text {cont }}=\tilde{c}_{3}^{\text {cont }}<\tau_{3}^{\text {coop }}=c_{3}^{\text {coop }}$. Therefore, if $c_{3}^{\text {cont }}>0$, $c_{3}^{\text {coop }}>c_{3}^{\text {cont }}$.

\section{Proof of Statement 2}

First, recall that $c_{3}^{\text {coop }} \in\left\{\tilde{c}_{3}^{\text {coop }}, c_{1}\right\}$ given $c_{3}^{\text {coop }}>0$. If $c_{3}^{\text {coop }}=c_{1}$, then the statement must be true.

Therefore, we consider situations in which $\widetilde{c}_{3}^{\text {coop }}$ exists and $c_{3}^{\text {coop }}=\widetilde{c}_{3}^{\text {coop }}$.

Consider the following three situations:

(1) Suppose that $0<c_{3}^{\text {cont }}<c_{1}$.

Then, by Lemma $1, c_{3}^{\text {cont }}=\widetilde{c}_{3}^{\text {cont }}$, the unique point such that $U_{3}^{\text {cont }},\left(c_{3}\right)=0$ in the strictly concave region of $U_{3}^{\text {cont }}$ when $c_{3}>x-c_{1}+c_{2}$. That is, $\partial U_{3}^{\text {cont }} /\left.\partial c_{3}\right|_{\tau_{3} \text { cont }}=0$ and $\partial U_{3}^{\text {cont }} /\left.\partial c_{3}\right|_{c_{3}}<0$ for any $c_{3}>\widetilde{c}_{3}^{\text {cont }}$. Following the logic in Statement $1, \partial U_{3}^{\text {coop }} /\left.\partial c_{3}\right|_{\widetilde{c}_{3}} ^{\text {cont }}>\partial U_{3}^{\text {cont }} /\left.\partial c_{3}\right|_{\tau_{3} \text { cont }}=0$ as $\tilde{c}_{3}^{\text {cont }}>c_{1}$ implies $\pi_{3}>\pi_{1}$. Therefore, $\widetilde{c}_{3}^{\text {coop }}>\widetilde{c}_{3}^{\text {cont }}$. Similarly, $\partial U_{3}^{\text {coop }} /\left.\partial c_{3}\right|_{c_{3}}<\partial U_{3}^{\text {cont }} /\left.\partial c_{3}\right|_{c_{3}}<0$ for any $c_{3}>c_{1}>\widetilde{c}_{3}^{\text {cont }}$, as $c_{3}>c_{1}$ implies $\pi_{3}<\pi_{1}$. Therefore, $\widetilde{c}_{3}^{\text {coop }} \leq c_{1}$. Therefore, as $c_{3}^{\text {coop }}=\widetilde{c}_{3}^{\text {coop }}$ by assumption, it must be that $c_{3}^{\text {cont }}<c_{3}^{\text {coop }} \leq c_{1}$ and $\left|c_{3}^{\text {coop }}-c_{1}\right| \leq\left|c_{3}^{\text {cont }}-c_{1}\right|$.

(2) Suppose that $0<c_{1}<c_{3}^{\text {cont }}$.

Then, by Lemma $1, c_{3}^{\text {cont }}=\widetilde{c}_{3}^{\text {cont }}$, the unique point such that $U_{3}^{\text {cont }},\left(c_{3}\right)=0$ in the strictly concave region of $U_{3}^{\text {cont }}$ when $c_{3}>x-c_{1}+c_{2}$. That is, $\partial U_{3}^{\text {cont }} /\left.\partial c_{3}\right|_{\tau_{3} \text { cont }}=0$ and $\partial U_{3}^{\text {cont }} /\left.\partial c_{3}\right|_{c_{3}}>0$ for any $c_{3}<\widetilde{c}_{3}^{\text {cont }}$. Following the logic in Statement $1, \partial U_{3}^{\text {coop }} / \partial c_{3}\left|\tau_{3}^{\text {cont }}<\partial U_{3}^{\text {cont }} / \partial c_{3}\right| \tau_{3}^{\text {cont }}=0$ as $\widetilde{c}_{3}^{\text {cont }}<c_{1}$ implies $\pi_{3}<\pi_{1}$. Therefore, $\widetilde{c}_{3}^{\text {coop }}<\widetilde{c}_{3}^{\text {cont }}{ }^{3}$ Similarly, $\partial U_{3}^{\text {coop }} /\left.\partial c_{3}\right|_{c_{3}}>\partial U_{3}^{\text {cont }} /\left.\partial c_{3}\right|_{c_{3}}>0$ for any $c_{3}<c_{1}<\widetilde{c}_{3}^{\text {cont }}$, as $c_{3}<c_{1}$ implies $\pi_{3}>\pi_{1}$. Therefore, $\widetilde{c}_{3}^{\text {coop }} \geq c_{1}$. Therefore, as $c_{3}^{\text {coop }}=\widetilde{c}_{3}^{\text {coop }}$ by assumption, it must be that $c_{3}^{\text {cont }}>c_{3}^{\text {coop }} \geq c_{1}$ and $\left|c_{3}^{\text {coop }}-c_{1}\right| \leq\left|c_{3}^{\text {cont }}-c_{1}\right|$.

(3) Suppose that $c_{3}^{\text {cont }}=c_{1}$ :

Then, by Lemma $1, c_{3}^{\text {cont }}=\widetilde{c}_{3}^{\text {cont }}$, the unique point such that $U_{3}^{\text {cont }},\left(c_{3}\right)=0$ in the strictly concave region of $U_{3}^{\text {cont }}$ when $c_{3}>x-c_{1}+c_{2}$. That is, $\partial U_{3}^{\text {cont }} /\left.\partial c_{3}\right|_{c_{1}}=0$ and $\partial U_{3}^{\text {cont }} /\left.\partial c_{3}\right|_{c_{3}}>0$ for any $c_{3}<c_{1}$ and $\partial U_{3}^{\text {cont }} /\left.\partial c_{3}\right|_{c_{3}}<0$ for any $c_{3}>c_{1} . \partial U_{3}^{\text {coop }} /\left.\partial c_{3}\right|_{c_{1}}$ does not exist due to the discontinuity at the point $c_{1}$. Following the logic in Statement $1, \partial U_{3}^{\mathrm{coop}} /\left.\partial c_{3}\right|_{c_{3}}>0$ for any $c_{3}<c_{1}$ and $\partial U_{3}^{\text {coop }} /\left.\partial c_{3}\right|_{c_{3}}<0$ for any $c_{3}>c_{1}$. Therefore, as defined, $\widetilde{c}_{3}^{\text {coop }}$ does not exist and therefore $c_{3}^{\text {coop }}=c_{1}$. Therefore $0=\left|c_{3}^{\text {coop }}-c_{1}\right| \leq\left|c_{3}^{\text {cont }}-c_{1}\right|=0$.

\section{Proof of Statement 3}

First, if $c_{3}^{\text {cont }}=0$, then $c_{3}^{\text {comp }} \geq c_{3}^{\text {cont }}$ as $c_{3}^{\text {comp }} \geq 0$ (contributions must be weakly positive).

Next, if $c_{3}^{\text {cont }}>0$, we will show that $c_{3}^{\text {coop }}>c_{3}^{\text {cont }}$. Now, given Lemma 1 , we know that $c_{3}^{\text {cont }}=\widetilde{c}_{3}^{\text {cont }}{ }^{3}$ and $c_{3}^{\text {comp }} \in\left\{0, \widetilde{c}_{3}^{\text {comp }}, c_{1}\right\}$. Note that Lemma 3 implies that $c_{3}^{\text {comp }} \neq 0$. Therefore $c_{3}^{\text {comp }} \in\left\{\widetilde{c}_{3}\right.$ comp,$\left.c_{1}\right\}$. Next, we will show that $\widetilde{c}_{3}^{\text {comp }}>\widetilde{c}_{3}^{\text {cont }}$. Recall that $\widetilde{c}_{3}^{\text {cont }}$ is the unique point such that $U_{3}^{\text {cont }},\left(c_{3}\right)=0$ when $c_{3}>x-c_{1}+c_{2}$. That 
is, $\partial U_{3}^{\text {cont }} / \partial c_{3} \mid \tau_{3}^{\text {cont }}=w \cdot P^{\prime}\left(c_{1}-c_{2}+c_{3}^{\text {cont }}\right)-1=0$ and $\tilde{c}_{3}^{\text {cont }}>x-c_{1}+c_{2}$ must be true.

Now, consider

$$
\begin{aligned}
& w \cdot P^{\prime}\left(c_{1}-c_{2}+\widetilde{c}_{3}^{\text {cont }}\right) \quad \text { if } \pi_{3}>\pi_{2} \\
& \partial U_{3}^{\mathrm{comp}} /\left.\partial c_{3}\right|_{\tau_{3}^{\mathrm{cont}}}=\begin{array}{c}
(1-2 \rho+2 \theta)-(1-\rho+\theta) \\
w \cdot P^{\prime}\left(c_{1}-c_{2}+\widetilde{c}_{3}^{\mathrm{cont}}\right)
\end{array} \quad \text { if } \pi_{3} \leq \pi_{2} \\
& (1-2 \sigma+2 \theta)-(1-\sigma+\theta)
\end{aligned}
$$

As $w \cdot P^{\prime}\left(c_{1}-c_{2}+c_{3}^{\text {cont }}\right)=1$, this can be rewritten as:

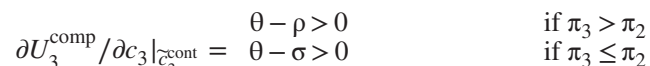

With the inequalities noted holding as $\theta>\rho>\sigma$ by assumption. As $\widetilde{c}_{3}^{\text {cont }}>x-c_{1}+c_{2}, U_{3}^{\text {comp }}$ must be concave at $\widetilde{c}_{3}^{\text {cont }}$ by Lemma 1 . Therefore, $\widetilde{c}_{3}^{\text {comp }}>\widetilde{c}_{3}^{\text {cont }}$.

We then know that $c_{3}^{\text {comp }} \in\left\{\widetilde{c}_{3}^{\text {comp }}, c_{1}\right\}, c_{3}^{\text {cont }}=\widetilde{c}_{3}^{\text {cont }}$, and $\widetilde{c}_{3}^{\text {comp }}>\widetilde{c}_{3}^{\text {cont }}$. If $\widetilde{c}_{3}^{\text {cont }} \leq c_{2}$, then $c_{3}^{\text {cont }}=\widetilde{c}_{3}^{\text {cont }} \leq$ $\left\{\widetilde{c}_{3}^{\text {comp }}, c_{2}\right\} c_{3}^{\text {comp }}$ If $\widetilde{c}_{3}^{\text {cont }}>c_{2}$, Lemma $3 \mathrm{~b}$ proves that $c_{3}^{\text {comp }} \neq c_{2}$ and therefore $c_{3}^{\text {comp }}=\tau_{3}^{\text {comp }}$, and therefore $c_{3}^{\text {cont }}=\widetilde{c}_{3}^{\text {cont }}<\widetilde{c}_{3}^{\text {comp }}=c_{3}^{\text {comp }}$. Therefore, if $c_{3}^{\text {cont }}>0$, $c_{3}^{\text {comp }}>c_{3}^{\text {cont }}$.

\section{REFERENCES}

Bornstein, G., and M. Ben-Yossef. "Cooperation in Intergroup and Single-Group Social Dilemmas." Journal of Experimental Social Psychology, 30(1), 1994, 52-67.

Bornstein, G., U. Gneezy, and R. Nagel. "The Effect of Intergroup Competition on Group Coordination: An Experimental Study." Games and Economic Behavior, 41(1), 2002, 1-25.

Charness, G., and M. Rabin. "Understanding Social Preferences with Simple Tests." Quarterly Journal of Economics, 117(3), 2002, 817-69.

Chen, Y., and S. X. Li. "Group Identity and Social Preferences." American Economic Review, 99(1), 2009, 431-57.

Corazzini, L., M. Faravelli, and L. Stanca. "A Prize to Give For: An Experiment on Public Good Funding Mechanisms." Economic Journal, 120, 2009, 944-67.

DeJong, W., and A. J. Oopik. "Effect of Legitimizing Small Contributions and Labeling Potential Donors as 'Helpers' on Responses to a Direct Mail Solicitation for Charity." Psychological Reports, 71(3), 1992, 923-28.

Desmet, P., and F. M. Feinberg. "Ask and Ye Shall Receive: The Effect of the Appeals Scale on Consumers' Donation Behavior." Journal of Economic Psychology, 24(3), 2003, 349-76.

Eckel, C. C., and P. J. Grossman. "Subsidizing Charitable Contributions: A Natural Field Experiment Comparing Matching and Rebate Subsidies." Experimental Economics, 11(3), 2008, 234-52.

Eliaz, K., T. Offerman, and A. Schotter. "Creating Competition Out of Thin Air: An Experimental Study of RightTo-Choose Auctions." Games and Economic Behavior, 62, 2008, 383-416

Erev, I., G. Bornstein, and R. Galili. "Constructive Intergroup Competition as a Solution to the Free Rider Problem: A Field Experiment." Journal of Experimental Social Psychology, 29(6), 1993, 463-78.
Falk, A. "Gift Exchange in the Field." Econometrica, 75(5), 2007, 1501-11.

Filiz-Ozbay, E., and E. Ozbay. "Auctions with Anticipated Regret: Theory and Experiment." American Economic Review, 97(4), 2007, 1407-18.

Fischbacher, U., S. Gächter, and E. Fehr. "Are People Conditionally Cooperative? Evidence from a Public Goods Experiment." Economics Letters, 71(3), 2001, 397-404.

Fraser, C., R. E. Hite, and P. L. Sauer. "Increasing Contributions in Solicitation Campaigns: The Use of Large and Small Anchorpoints." Journal of Consumer Research, 15, 1988, 284-87.

Frey, B. S., and S. Meier. "Social Comparisons and Pro-Social Behavior: 'Testing Conditional Cooperation' in a Field Experiment." American Economic Review, 94(5), 2004, $1717-22$.

Huck, S., and I. Rasul. "Matched Fundraising: Evidence from a Natural Field Experiment." Journal of Public Economics, 95(5), 2011, 351-62.

King, G., and L. Zeng. "Logistic Regression in Rare Events Data." Political Analysis, 9(2), 2001, 137-63.

Lange, A., J. A. List, and M. K. Price. "A Fundraising Mechanism Inspired by Historical Tontines: Theory and Experimental Evidence." Journal of Public Economics, 91(9), 2007, 1750-82.

List, J. A., and D. Lucking-Reiley. "The Effects of Seed Money and Refunds on Charitable Giving: Experimental Evidence from a University Capital Campaign." Journal of Political Economy, 110(1), 2002, 215-33.

Morgan, J., K. Steiglitz, and G. Reis. "The Spite Motive and Equilibrium Behavior in Auctions." BE Journal: Contributions to Economic Analysis and Policy, 2(1), 2003, 1102-27.

Ockenfels, A., and R. Selten. "Impulse Balance Equilibrium and Feedback in First Price Auctions." Games and Economic Behavior, 51, 2005, 155-170.

Onderstal, S., A. Schram, and A. Soetevent. "Bidding to Give in the Field." Journal of Public Economics, 105, 2013, $72-85$.

Rapoport, A., and G. Bornstein. "Intergroup Competition for the Provision of Binary Public Goods." Psychological Review, 94(3), 1987, 291.

Schibrowsky, J. A., and J. W. Peltier. "Decision Frames and Direct Marketing Offers: A Field Study in a Fundraising Context." Journal of Direct Marketing, 9(1), 1995, $8-16$.

Shang, J., and R. Croson. "The Impact of Social Comparisons on Nonprofit Fund Raising." Research in Experimental Economics, 11, 2006, 143-56.

. "A Field Experiment in Charitable Contribution: The Impact of Social Information on the Voluntary Provision of Public Goods." The Economic Journal, 119(540), 2009, 1422-39.

Shang, J., A. Reed, and R. Croson. "Identity Congruency Effects on Donations." Journal of Marketing Research, 45(3), 2008, 351-61.

Smith, G. E., and P. D. Berger. "The Impact of Direct Marketing Appeals on Charitable Marketing Effectiveness." Journal of the Academy of Marketing Science, 24(3), 1996, 219-31.

Weyant, J. M. "Application of Compliance Techniques to Direct-Mail Requests for Charitable Donations." Psychology \& Marketing, 13(2), 1996, 157-70. 